\title{
IMPACTOS DA ASCENSÃO DA CHINA SOBRE A ECONOMIA BRASILEIRA: COMÉRCIO E CONVERGÊNCIA CÍCLICA $(*)^{* *) 1}$
}

\author{
André Moreira Cunha ${ }^{* * *}$ \\ Julimar da Silva Bichara ${ }^{* * * *}$ \\ Sandro Eduardo Monsueto ${ }^{* * * * *}$ \\ Marcos Tadeu Caputi Lélis
}

RESUMO: A ascensão chinesa à condição de potência econômica e política no âmbito global tem estado no centro dos debates acadêmicos e políticos. Neste trabalho analisamos alguns impactos desse evento marcante sobre o Brasil. Mais especificamente, investigamos o comércio bilateral e os padrões de convergência cíclica entre as duas economias, considerando uma análise mais ampla da competitividade externa da economia brasileira. As conclusões exploram algumas implicações normativas dos nossos resultados.

PALAVRAS-CHAVE: Brasil; China; comércio internacional; ciclos de negócios.

CLASSIFICAÇÃO JEL: F14; F41; F59.

* Artigo aceito em 05/11/2010 e aprovado em 23/11/2011.

** Os autores agradecem os comentários dos pareceristas anônimos. Erros e omissões restantes são de inteira responsabilidade dos autores. Lembramos, ainda, que a análise aqui realizada reflete exclusivamente a opinião dos autores, não coincidindo, necessariamente, com a visão de suas instituições de origem.

${ }^{1}$ Esta é uma versão condensada e atualizada de um trabalho apresentado no "II Seminário sobre Pesquisas em Relações Econômicas Internacionais", organizado pelo MRE no dia 4 de março de 2010 em Brasília DF. Agradecemos ao apoio do CNPq e da APEX-Brasil no desenvolvimento deste trabalho. As opiniões aqui expressas são de inteira responsabilidade dos seus autores e não refletem, necessariamente, a posição oficial de suas instituições de origem.

*** Doutor em Economia pela Unicamp, professor do PPGE-UFRGS e pesquisador do CNPq, Contato: andre.cunha@ufrgs.br.

**** Doutor em Economia pela Universidad Autónoma de Madrid e professor da mesma instituição. Contato: julimar.dasilva@uam.es.

***** Doutor em Economia pela Universidad Autónoma de Madrid e professor do Departamento de Ciências Econômicas da UFG. Contato: monsueto@face.ufg.br.

***** Doutor em Economia pela UFRGS e coordenador da Unidade de Inteligência Comercial e Competitiva da APEX-Brasil. Contato: mcaputi@uol.com.br. 


\section{CHINA'S RISE AND ITS IMPACTS ON BRAZILIAN ECONOMY: TRADE AND BUSINESS CYCLES CONVERGENCE}

ABSTRACT: Since early 2000's, China's rise as a global economic and political power has been at the forefront of academic and political debates. In this paper we analyze some impacts of this watershed event on Brazil. More specifically, we investigate the evolution of bilateral trade and business cycle patterns of convergence between those two countries, considering a broader analysis of Brazilian external competitiveness. We conclude exploring some normative implications of our findings.

KEYWORDS: Brazil; China; international trade; business cycles. 


\section{INTRODUÇÃO}

A ascensão da China à condição de potência econômica tem sido um dos fatos mais marcantes deste começo de século XXI. Seus possíveis efeitos sobre o sistema internacional, em dimensões econômica e política, têm concentrado a atenção de especialistas das mais diversas áreas. No que se refere ao caso da América Latina, os efeitos da ascensão chinesa têm sido objeto de vários estudos. Conforme tem sido destacado pela literatura recente, o comércio de mercadorias entre a China e os países latino-americanos vem crescendo a taxas significativamente superiores àquelas verificadas para o total transacionado na região. No período recente, a China também tem se destacado como origem de investimento direto (CAF, 2006; Devlin, Estevadeordal e Rodriguez, 2006; Lederman, Olarreaga e Perry; 2008; Jenkins, 2010 CEPAL, 2011).

É importante destacar algumas características das relações comerciais entre os países da região e a China, quais sejam:

(i) Os fluxos de comércio crescem de forma mais veloz entre tais economias do que a média dos demais destinos de exportações e origens de importações;

(ii) Há pelo menos dois padrões de comércio claramente delineados: aquele identificado com a experiência mexicana e centro-americana, onde predominam déficits com a China; e aquele verificado nos países sul-americanos, onde é possível identificar períodos de superávits sustentados pelo boom das exportações de commodities primárias e energéticas, além de manufaturas de baixo conteúdo tecnológico;

(iii) Nos dois casos o perfil de comércio vem se alterando ao longo do tempo em um sentido de redução do conteúdo tecnológico dos produtos exportados para a China e ampliação daquele conteúdo nas importações ${ }^{2}$.

Os analistas têm se divido entre aqueles mais otimistas quanto aos efeitos da ascensão chinesa sobre a região latino-americana, tais como Devlin, Estevadeordal e Rodríguez-Clare (2006) e Blazquez-Lidoy, Rodrıguez, Santiso (2006), e os céticos ou pessimistas, como Moreira (2006), Phillips (2007), Paus (2009) e Jenkins (2010). No primeiro grupo, argumenta-se que o crescimento chinês, intensivo na demanda de recursos naturais, tende a criar uma janela de oportunidade para a expansão das exportações da região, bem como para a atração de investimentos na área de infraestrutura. Mesmo reconhecendo esses aspectos, o segundo grupo de autores teme que a especialização na produção e exportação de recursos naturais, associada à concorrência dos produtos chineses nos mercados domésticos e em terceiros mercados, represente um grave risco para as economias com estruturas produtivas mais maduras.

\footnotetext{
${ }^{2}$ É verdade que tal perfil não destoa do padrão histórico da região, cujas exceções mais notórias são Brasil e México, que apresentam estruturas produtivas e pautas de comércio mais diversificadas.
} 
A concentração produtiva e exportadora em recursos naturais remete aos problemas clássicos já apontados pelos pioneiros do pensamento estruturalista latino-americano, como Prebisch (1950 e 1984) e Furtado (1961 e 2003). A conformação de economias duais, com efeitos perversos sobre o mercado de trabalho, a tendência ao desequilíbrio externo, à formação de uma elite econômica e política autoritária e consumista, que reproduz os padrões de consumo dos países centrais e promove a concentração interna da renda e do poder - para manter o controle sobre as rendas geradas pela natureza são alguns dos problemas recorrentes na história econômica dos países periféricos. É bem verdade que o ciclo recente de alta nos preços das commodities tem estado associado disseminação de políticas redistributivistas que estão dinamizando os mercados internos de muitos países na região e, pelo menos em curto prazo, garantindo uma combinação virtuosa de expansão da renda com melhorias distributivas.

Assim, não se está assumindo aqui que, a priori, a ascensão chinesa represente um bem ou um mal em si, mas sim que há claras vantagens e riscos que se colocam na trajetória das economias latino-americanas em geral e brasileira em particular, cujos desdobramentos dependem muito mais das estratégias locais de desenvolvimento do que do posicionamento chinês no mundo. Conforme se argumenta ao longo deste trabalho, parece estar claro: a China percebe em países como o Brasil fontes para suprimento de recursos naturais e mercados de absorção de suas exportações de manufaturas. Se deixada ao sabor dessas circunstâncias, a tendência predominante poderá ser a de uma regressão produtiva e institucional, com a China ascendendo ao centro e o Brasil, com os demais países da região, cristalizados na renovada periferia global do século XXI.

O caso brasileiro é representativo do debate sobre as possibilidades de desenvolvimento da América Latina no século XXI ${ }^{3}$ (Acioly, Pinto e Cintra, 2011). Aqui também é possível identificar pelo menos duas perspectivas sobre esse tipo de formulação. Aceitando os riscos derivados do excesso de simplificação, sugere-se denominá-las de visões "otimista" e "pessimista". A primeira percebe na ascensão

\footnotetext{
${ }^{3}$ Por isso mesmo, causa certa estranheza que os trabalhos produzidos por instituições internacionais para avaliar as perspectivas latino-americanas pouco explorem, com a devida profundidade, o caso brasileiro. Argentina, Chile e México são exaustivamente estudados, ficando o Brasil, que é a principal economia da região e a única a poder ambicionar um projeto renovado de desenvolvimento com ampliação regional de seus efeitos, em um segundo plano. Argentina e Chile não têm tamanho e diversificação produtiva para liderarem um projeto regional de desenvolvimento, ao passo que o México, assim como os países da América Central e Caribe abriram mão desta possibilidade em seus acordos de integração econômica com os EUA.

${ }^{4}$ As referências estão, dentre outros, em Fujita (2001), Castro (2008) e Conferência Nacional (2009). Para o contexto latino-americano, ver CAF (2006), Devlin, Estevadeordal e Rodriguez (2006), Lederman, Olarreaga e Perry (2008) e CEPAL $(2006,2008,2009)$.
} 
chinesa a possibilidade de consolidação de uma nova ordem internacional, menos centrada no poder americano e com maior abertura de espaços para que o Brasil se consolide como uma potência líder entre os países em desenvolvimento, particularmente na América do Sul (e, também, com capacidade de influenciar nações africanas que compartilham a herança comum da colonização portuguesa). A demanda chinesa por recursos naturais criaria um vetor de dinamismo para a economia brasileira ao longo dos próximos anos, o que permitiria a ruptura do quadro de semiestagnação derivado da crise da dívida externa dos anos 1980. Evidentemente, a demanda chinesa per se não teria esse poder indutor, sendo percebida como uma alavanca para a internacionalização de setores produtivos especializados na produção e industrialização de bens intensivos em recursos naturais.

Por outro lado, a visão "pessimista" olha para essa mesma possibilidade como sendo um risco de involução, com o Brasil retornando a uma posição semelhante àquela dos anos pré-1930, de uma economia primário-exportadora. Teme-se aqui a perda de densidade da estrutura industrial diante das pressões competitivas originadas na China, com efeitos negativos sobre a capacidade de gerar emprego e renda em setores produtivos mais complexos. Avalia-se, também, que a crescente presença econômica da China na América do Sul e na África poderia reduzir o potencial de internacionalização da economia brasileira.

Nos marcos desse tipo de discussão, o presente artigo procura contribuir trazendo evidências sobre o perfil das relações econômicas bilaterais entre Brasil e China. Parte-se da constatação de que há uma carência de estudos enfatizando certas dimensões do perfil de relações comerciais e de convergência de ciclos econômicos, particularmente quando se considera o caso brasileiro. Há, de fato, uma crescente literatura que avalia os impactos da ascensão chinesa sobre a América Latina, com eventuais estudos de caso, porém sem um destaque particular para o Brasil. Além disso, torna-se necessário ampliar as discussões sobre as implicações daquela ascensão sobre a economia brasileira. Para atingir tais objetivos, parte-se de uma discussão sobre o modelo de crescimento e internacionalização da China. Argumenta-se que, tanto no ciclo de expansão, entre 2003 e 2008, quanto na crise financeira global, o comportamento da economia mundial em geral, e da economia brasileira, em particular, tem estado fortemente condicionado pelo movimento de expansão global da China.

Na sequência são fornecidas algumas evidências do padrão de comércio bilateral Brasil-China, por meio de indicadores de desempenho e competitividade, bem como é estimado o grau de convergência cíclica entre essas duas economias. Para avaliar o comércio bilateral são utilizados indicadores que comparam os potenciais e a intensidade de comércio do Brasil e a China. Sempre que possível, os indicadores são calculados utilizando-se uma desagregação a três dígitos segundo a classificação 
HS (Harmonized Commodity Description and System Code). Para a convergência cíclica, utiliza-se a metodologia desenvolvida por Frenkel e Rose (1998) e Calderón (2008), dentre outros. Por fim, considerando os impactos da crise global e os vínculos cada vez mais estreitos entre essas duas economias, conclui-se com uma discussão sobre os riscos e oportunidades para o Brasil, derivados da ascensão chinesa.

\section{A ASCENSÃO DA CHINA E AS ECONOMIAS LATINO-AMERICANAS}

É possível localizar no final dos anos 1970 a inflexão chinesa rumo a uma trajetória mais robusta de modernização (Zheng Bijian, 2005 e 2006, Shirk, 2007, Leonard, 2008). O crescimento econômico por meio de reformas que ampliaram os espaços dos mercados podem ser percebidos como "meios" necessários à viabilização de um "fim" maior, qual seja a recuperação de uma posição hierarquicamente superior na ordem internacional (Wu Jiglian, 2005 e 2006, Leonard, 2008). Da mesma forma, para viabilizar o "rejuvenescimento da nação", combinando crescimento com manutenção da "ordem interna", sob o estrito controle do Partido Comunista, as lideranças chinesas têm revelado que estão conscientes de que o país necessita de recursos naturais, novas capacidades tecnológicas, acesso a mercados etc., o que envolve a construção de uma teia ampla de relações políticas na arena internacional.

Países sul-americanos em geral, e o Brasil, em particular, respondem a parte dessas necessidades. A fome chinesa por matérias-primas e mercados já se faz sentir com intensidade inédita na região, conforme tem sido sugerido por inúmeros trabalhos (Zweig e Jianhai, 2005; Trinh, Voss e Dick, 2006; CAF, 2006; Devlin, Estevadeordal e Rodriguez, 2006; Lederman, Olarreaga e Perry, 2008; CEPAL, 2006, 2008, 2009). A ampliação dos fluxos de comércio e investimentos é a face econômica mais evidente desse processo. Tal aproximação se dá em um momento de reordenamento dos espaços de poder em âmbito internacional. Projeções feitas nos últimos anos sugerem que a China deverá se tornar, ainda na primeira metade do século XXI, a maior economia do planeta. No plano comercial, o país é um dos três maiores global players, junto à Alemanha e aos Estados Unidos. Note-se que, em meados dos anos 1980, a China representava cerca de $1 \%$ das exportações mundiais - peso equivalente ao do Brasil -, atingindo, em 2008, uma participação de 8,9\%. A partir do começo dos anos 1990, a China tornou-se a nação em desenvolvimento que mais absorveu investimento direto externo (IDE). Recentemente, além de receptor o país também se tornou fonte de investimentos, especialmente em outros países periféricos. $\mathrm{O}$ drive exportador chinês vem impondo uma crescente pressão competitiva sobre economias industrializadas e em desenvolvimento. Sua demanda por matérias-primas e energia afeta, cada vez mais, a distribuição mundial da oferta e dos preços das commodities, com distintos impactos sobre outros países, produtores e consumidores. 
É nesse processo de rápida ascensão, caracterizada por suas lideranças políticas e intelectuais como tendo um caráter pacífico, que a China adentrou o século XXI como membro da OMC e, junto aos EUA, como motor do crescimento global. Entre 2003 e 2008 (primeiro semestre) a economia mundial viveu um ciclo de expansão excepcionalmente favorável. Tal caráter "excepcional" se deveu à confluência de alguns fatores, principalmente: crescimento elevado - com taxas médias de variação no PIB global acima de 4\% - associado à inflação baixa (pelo menos até meados de 2007); retomada de dinamismo em regiões que, nos anos 1980 e 1990, apresentaram níveis baixos de expansão da renda, tais como América Latina, África e Leste Europeu, ou em economias maduras como Japão e Alemanha; melhoria substancial nos resultados das contas externas e nas finanças públicas das economias em desenvolvimento previamente caracterizadas por níveis elevados de vulnerabilidade externa e fragilidade fiscal. Essas características brotaram em um momento em que a estrutura da economia revelava uma nova realidade: economias emergentes, como China, Índia, Rússia, Brasil, dentre outras, passaram a ter um peso na renda mundial, nos fluxos de comércio e na determinação do ritmo de expansão equivalentes ou superiores aos das economias centrais (Goldman Sachs, 2007, El-Erian, 2008). Dados do FMI (2008a e 2009a) sugerem que em 2007 e 2008 mais da metade do PIB global, medido em paridade poder de compra, era gerado nos países em desenvolvimento.

Com explicar essa situação especial? Em grande medida ela foi produzida pela convergência de fatores conjunturais e de uma transformação estrutural que, então, se explicitou com muita intensidade. Do ponto de vista conjuntural, as principais economias avançadas, particularmente os EUA, reagiram ao ambiente de menor crescimento e de instabilidade financeira do começo dos anos 2000, por meio de políticas monetárias e fiscais largamente expansionistas. Nos EUA, Greenspan comandou uma redução da FED Fund Rate do patamar de 6,5\% (maio de 2000) ao ano para 1\% (junho de 2003), o que facilitou a digestão dos passivos acumulados no período de euforia anterior, evitando que a ruptura financeira ainda mais grave do que a contração verificada em função da bolha especulativa da Nasdaq e dos escândalos corporativos. Havia um temor de que os problemas do mercado acionário contaminassem, ainda mais, o lado real da economia estadunidense. Por sua vez, a gestão fiscal do novo governo republicano (George W. Bush, 2001-2009) transformou a herança de superávits do governo Clinton (1993-2001) em déficits crescentes, dados os aumentos de gastos e as reduções de impostos.

Conforme tem sido destacado pela literatura recente (CAF, 2006; Devlin, Estevadeordal e Rodriguez, 2006; Lederman, Olarreaga e Perry, 2008; CEPAL, 2006, 2008, 2009) o comércio de mercadorias entre a China e os países latino-americanos vem crescendo a taxas significativamente superiores àquelas verificadas para o total 
transacionado na região. Tomando-se por referência o ano de 2008, e considerando-se o conjunto da América Latina e Caribe, a China representou 3,9\% das exportações - US\$ 31 bilhões de um total de US\$ 782 bilhões - e 10,8\% das importações - US\$ 80 bilhões de um total de US\$ 739 bilhões - o que implicou um déficit de US\$ 49 bilhões. Para se colocar em perspectiva, no ano de 2000 as participações da China nas exportações e importações da região eram de, respectivamente, $0,9 \%$ e 2,2\%. Para os países do MERCOSUL, a China representava, em 2000, 2,4\% das exportações e 3,2\% das importações. Em 2008, tais proporções eram de, respectivamente, 8,3\% e 12,3\%.

É importante destacar algumas características das relações comerciais entre os países da região e a China, quais sejam:

(i) Os fluxos de comércio crescem de forma mais veloz entre tais economias do que a média dos demais destinos de exportações e origens de importações;

(ii) Há pelo menos dois padrões de comércio claramente delineados: aquele identificado com a experiência mexicana e centro-americana, onde predominam déficits com a China; e aquele verificado nos países sul-americanos, onde é possível identificar períodos de superávits sustentados pelo boom das exportações de commodities primárias e energéticas, além de manufaturas de baixo conteúdo tecnológico;

(iii) Nos dois casos o perfil de comércio vem se alterando ao longo do tempo no sentido de redução do conteúdo tecnológico dos produtos exportados para a China e ampliação daquele conteúdo nas importações ${ }^{5}$.

O caso brasileiro é representativo desse padrão. No ano de 2009, a China se transformou no principal parceiro comercial do Brasil, papel antes ocupado pelos EUA. O gigante asiático absorveu 13,2\% das exportações brasileiras e originou 12,5\% das importações. Em termos da corrente de comércio, China e EUA, têm proporções semelhantes, de $13 \%$. No ano de 2000, o peso da China no comércio exterior do país era de 2\%. Desde então, conforme pode ser observado no Gráfico 1 (Apêndice), o ritmo de expansão do comércio bilateral foi mais intenso do que o verificado no conjunto do comércio exterior brasileiro. No ciclo de alta de preços das matérias-primas, depois de 2003, os superávits brasileiros foram crescentes, com exceção dos anos de 2007 e 2008.

Como também é típico da experiência latino-americana, as exportações brasileiras têm se concentrado cada vez mais em produtos de baixo conteúdo tecnológico. Assim, por exemplo, dois produtos, soja e minério de ferro, vêm representando mais de 2/3 do total exportado pelo Brasil. O Gráfico 2 (Apêndice) toma a classificação setorial da CEPAL (2009) sobre a intensidade tecnológica dos produtos e mostra

\footnotetext{
${ }^{5}$ É verdade que tal perfil não destoa do padrão histórico da região, cujas exceções mais notórias são Brasil e México, que apresentam estruturas produtivas e pautas de comércio mais diversificadas.
} 
a evolução das exportações brasileiras para a China e as importações originadas naquele país. Em 2008, 90\% dos produtos exportados pelo Brasil eram intensivos em recursos naturais, in natura ou processados. Tal proporção era de 53\% em 1990. Por outro lado, as importações evoluíram no sentido contrário, com ampliação na participação dos setores de média e alta tecnologia. Tendo por base essa breve caracterização, a próxima seção analisa com mais detalhes o comércio bilateral e a convergência cíclica entre Brasil e China.

\section{A CHINA E A ECONOMIA BRASILEIRA: COMÉRCIO, CICLO E CRESCIMENTO}

De acordo com a literatura referida na Introdução deste trabalho, a ascensão da China à condição de potência econômica global pode vir a reforçar um padrão potencialmente regressivo de inserção comercial externa para a economia brasileira, qual seja a de fornecedora, primordialmente, de produtos intensivos em recursos naturais. A demanda das economias maduras e emergentes por tais produtos, associada à crescente concorrência internacional nos mercados de manufaturas, seriam dois fenômenos diretamente associados à emergência chinesa. Por conta disso, esta seção procura, em um primeiro momento, caracterizar o padrão o desempenho das exportações brasileiras no período 1999-2008, onde se reafirma aquela tendência, qual seja a de que o Brasil está se posicionando, cada vez mais, como exportador de produtos primários e manufaturados intensivos em recursos naturais, enquanto a China diversifica e sofistica sua base exportadora. Esse padrão reaparece no exercício econométrico realizado na subseção 3.2, que utiliza a metodologia dos modelos gravitacionais, e constata que o comércio internacional tem gerado maior convergência cíclica entre a economia brasileira e as economias parceiras utilizadas no estudo, especialmente a China.

\subsection{PADRÕES DE COMÉRCIO: BRASIL, CHINA E OUTROS PARCEIROS ESTRATÉGICOS}

Esta seção analisa as principais características do comércio entre o Brasil e China. Nossas estimativas foram feitas levando em conta uma amostra de 23 países escolhidos como mercados prioritários para as ações de promoção comercial da APEX-Brasil ${ }^{6}$.

\footnotetext{
${ }^{6}$ A Agência Brasileira de Promoção de Exportações e Investimentos definiu 23 países para priorizar suas ações, entre mercados prioritários - Angola, Argentina, Canadá, China, Colômbia, Coreia do Sul, Índia, Vietnã, Cuba, Egito, EUA, México, Noruega, Peru, Polônia, Rússia, e Venezuela - e países trader - África do Sul, Chile, Cingapura, Emirados Árabes, Panamá, e Turquia. Na média do período 2001-2008, tais países absorveram 54\% das exportações totais do Brasil.
} 
Foram calculados seis indicadores ${ }^{7}$ que comparam os potenciais e a intensidade de comércio do Brasil com seus parceiros internacionais, as vantagens do país frente a seus principais competidores, além do nível de diversificação das respectivas pautas de exportação. Sempre que possível, os indicadores são calculados utilizando-se uma desagregação a três dígitos, segundo a classificação HS.

Verifica-se que:

(i) Há uma ampliação na intensidade da relação comercial entre Brasil e China;

(ii) Que esse comércio tende a ser interindustrial, com o Brasil se especializando como fornecedor de produtos intensivos em recursos naturais, nos quais revela vantagens comparativas;

(iii) Ademais, a pauta exportadora brasileira é mais concentrada do que a média dos países aqui analisados, especialmente nos setores de maior intensidade tecnológica.

O primeiro indicador a ser analisado é o índice de intensidade de comércio (IIC) ${ }^{8}$, normalmente utilizado para avaliar em que medida o valor transacionado entre dois países quaisquer é maior (ou menor) do que seria esperado quando se leva em consideração sua importância relativa no comércio internacional. Ele é definido como sendo a parcela das exportações do "país i” que se direciona para o "país j” dividido pela parcela das exportações mundiais que se direcionam a “j”. Um indicador maior (menor) do que um indica que os fluxos bilaterais de comércio são maiores (menores) do que o esperado, dado o peso do parceiro comercial no comércio mundial. O Gráfico 4 (Apêndice) sugere que, por esse critério, o comércio entre Brasil e China tem sido cada vez mais intenso, nos moldes do que já acontecida entre Brasil e EUA, e Brasil e Argentina.

Para os demais países da nossa amostra os índices foram, de forma predominante, superiores à unidade com destaque especial para os países latino-americanos, com exceção do México. Dos países com índice inferior à unidade, cabe destacar Canadá, a Índia e a Turquia, que se caracterizam por um tamanho de mercado substantivo e/ou com potencial de crescimento, mas cuja presença brasileira é inferior à média mundial.

$\mathrm{O}$ indicador de comércio intrassetorial (ICI), também conhecido como índice de Grubel Lloyd, procura capturar a importância relativa do comércio que se realiza dentro de um mesmo setor produtivo, o que normalmente está associado à exploração de economias de escala e escopo derivadas do acesso a mercados ampliados. Por meio do comércio intrassetorial um país pode ampliar sua especialização produtiva. Esse indicador varia entre zero e 100 e quanto mais próximo da centena maior o comércio

\footnotetext{
7 Todos os indicadores analisados tomam o Brasil como referência.

${ }^{8}$ Formalmente: $I C i j=(x i j / X i t) /(x w j / X w t)$. Onde: $x i j$ e $x w j$ são os valores exportados pelo "país $i$ " e pelo mundo " $w$ " para o "país j"; e Xit e Xwt são as exportações totais de “ $i$ " e “ $w$ ".
} 
realizado por empresas de um mesmo setor, sugerindo ganhos de especialização. Ou seja:

$$
I C I j k=(1-[\text { sumi }|X i j k-M i j k| /(X i j k+M i j k)])^{\star} 100
$$

Onde:

Xijk e Mijk representam as exportações e importações de produtos do "setor $i$ " no "país j” para e a partir do "país $k$ ”.

A análise tradicional desse índice define três níveis ou categorias que classificariam o padrão de comércio:

(i) Nível 1: ICI > 33 Padrão de comercio intraindustrial;

(ii) Nível 2: $10<I C I>33$ com potencial de comércio intraindustrial;

(iii) Nível 3: $I C I<10$ Padrão de comercio interindustrial.

O padrão de comércio intraindustrial, como destaca a nova teoria do comércio internacional, estaria associado à possibilidade de ganhos dinâmicos derivados do comércio, i.e., possibilidade de ganhos decorrentes de economias de escala de produção, da especialização, da racionalidade de custos, do aumento da produtividade e de vantagens competitivas. Desse modo, o crescimento do fluxo de comércio com esses países produziria um maior crescimento econômico, na medida em que possibilitaria uma ampliação da escala de produção, por exemplo, implicando maior produtividade e competitividade internacional.

O Gráfico 5 reporta que o comércio bilateral com a China tem um padrão interindustrial, diferentemente com o que ocorre no conjunto da amostra (APEX-23), em que predomina o comércio intrassetorial. Nesse caso, assim como no dos demais países asiáticos, reforça-se a percepção previamente destacada de que o Brasil tem se posicionado como um exportador de produtos intensivos em recursos naturais e importador de manufaturas de maior conteúdo tecnológico.

Por sua vez, o índice de vantagens comparativas reveladas (VCR) afere o potencial exportador de um país qualquer a respeito do resto do mundo. Países com indicadores similares tendem a exibir um baixo volume de comércio bilateral (salvo na presença de um intenso comércio intrassetorial), ao passo que divergências sugerem maior complementariedade e, por isso mesmo, potencial de expansão do comércio. Um indicador superior (inferior) à unidade indica uma vantagem (desvantagem) comparativa revelada naquele produto/setor a respeito do parceiro comercial. É calculado da seguinte forma:

$$
V C R i j=(x i p / X i) /(x p w / X w)
$$


Onde:

$x i p$ e $x p w$ correspondem às exportações do "produto $p$ " originado no "país $i$ " e "no mundo $w$ ", ao passo que $X i$ e $X w$ são as exportações totais do "país $i$ " e do "mundo $w$ ".

$\mathrm{O}$ indicador pode ser calculado também entre dois parceiros comerciais, países “” e “ $j$ ”. Os resultados do índice de VCR são apresentados na Tabela 1.

Tabela 1 - Índice de Vantagem Comparativa Revelada do Brasil com os parceiros estratégicos, 1999-2008

\begin{tabular}{|c|c|c|c|c|c|c|}
\hline Ano & Setor & BRA & APEX 23 & Argentina & China & EUA \\
\hline \multirow{6}{*}{$1999-2002$} & Primário & 1,860 & 1,110 & nd & 0,690 & 0,693 \\
\hline & Rec. Naturais & 1,393 & 0,963 & nd & 0,605 & 0,770 \\
\hline & Baixa Tecg & 1,115 & 0,928 & nd & 2,465 & 0,635 \\
\hline & Média Tecg & 0,810 & 0,908 & nd & 0,833 & 0,998 \\
\hline & Alta Tecg & 0,480 & 1,120 & nd & 0,893 & 1,563 \\
\hline & Outros & 0,515 & 1,020 & nd & 0,093 & 1,100 \\
\hline \multirow{6}{*}{$2003-2006$} & Primário & 1,958 & 1,118 & nd & 0,450 & 0,650 \\
\hline & Rec. Naturais & 1,243 & 1,023 & nd & 0,498 & 0,855 \\
\hline & Baixa Tecg & 1,108 & 1,008 & nd & 2,073 & 0,660 \\
\hline & Média Tecg & 0,868 & 0,878 & nd & 0,960 & 1,025 \\
\hline & Alta Tecg & 0,380 & 1,065 & nd & 1,283 & 1,538 \\
\hline & Outros & 0,443 & 0,965 & nd & 0,090 & 1,035 \\
\hline \multirow{6}{*}{2007} & Primário & 2,010 & 1,140 & 2,840 & 0,310 & 0,660 \\
\hline & Rec. Naturais & 1,170 & 1,010 & 1,600 & 0,470 & 0,910 \\
\hline & Baixa Tecg & 1,120 & 1,030 & 0,620 & 2,020 & 0,640 \\
\hline & Média Tecg & 0,760 & 0,900 & 0,530 & 1,100 & 1,040 \\
\hline & Alta Tecg & 0,430 & 1,010 & 0,160 & 1,300 & 1,530 \\
\hline & Outros & 0,650 & 0,930 & 0,430 & 0,080 & 1,040 \\
\hline \multirow{6}{*}{2008} & Primário & 2,070 & 1,150 & 2,830 & 0,300 & 0,760 \\
\hline & Rec. Naturais & 1,030 & 1,040 & 1,460 & 0,460 & 0,970 \\
\hline & Baixa Tecg & 1,190 & 1,060 & 0,540 & 2,050 & 0,650 \\
\hline & Média Tecg & 0,790 & 0,910 & 0,580 & 1,150 & 1,040 \\
\hline & Alta Tecg & 0,400 & 1,010 & 0,190 & 1,320 & 1,450 \\
\hline & Outros & 0,540 & 0,660 & 0,470 & 0,070 & 0,870 \\
\hline
\end{tabular}

Nota: nd - não disponível.

Fonte: Elaboração própria com dados do FMI-Directions Trade Statistics a três dígitos. 
Os resultados sugerem que o Brasil tende a perder vantagens comparativas em setores de maior intensidade tecnológica. Comparando-se os índices brasileiros com os da amostra APEX-23, constata-se que o Brasil é mais competitivo do que a média dos países da amostra nos setores de produtos primários e intensivos em recursos naturais e em baixa tecnologia, sendo menos competitivo nos setores de média e alta tecnologia. Esse resultado é semelhante quando se compara o Brasil com China e EUA. Com a Argentina as exportações brasileiras de baixa, média e alta tecnologia são mais competitivas. Por outro lado, a China mostra uma evolução no sentido de ser competitiva nos setores de maior sofisticação tecnológica.

Para reforçar a análise anterior é possível se empregar o indicador de especialização das exportações (IES), que é uma versão modificada do indicador de vantagens comparativas reveladas (VCR). A ênfase aqui é na relação de comércio bilateral entre dois países quaisquer, tomando em conta dados setoriais. Um indicador maior (menor) do que a unidade sugere uma vantagem (desvantagem) de especialização no setor em análise no mercado de destino. Portanto, um valor baixo revela uma pequena participação nas importações setoriais de parceiro comercial de referência, no entanto, o contrário implica em uma elevada quota de mercado, portanto, alto nível de competitividade no mercado considerado.

Temos:

$$
I E S=(x p i / X i t) /(m p j / M j)
$$

Onde:

$x p i$ e $X i$ são as exportações do produto/setor “ $p$ ” originados no "país $i$ ", enquanto $m p j$ e $M p$ são, respectivamente, as importações do "produto $p$ " no mercado $j$ e o total das importações de $j$.

Esse indicador revela vantagem (ou desvantagem) de especialização brasileira nos setores considerados em relação aos países da amostra. Como se observa na Tabela 2, os resultados são equivalentes aos encontrados para o indicador de vantagem comparativa revelada, i.e., o Brasil só tem vantagens competitivas em produtos primários ou manufaturas intensivas em recursos naturais, apresentando desvantagem relativa nos produtos intensivos em tecnologia (média e alta). Por outro lado, apresenta vantagem comparativa nos setores intensivos em tecnologia frente aos países latino-americanos (México é uma exceção) e africanos ${ }^{9}$. Portanto, confirma-se a deficiência competitiva

\footnotetext{
${ }^{9}$ Foram calculados os indicadores para todos os anos da série, i.e., de 1999 a 2008 , e todos os países da amostra. Os resultados podem ser disponibilizados mediante solicitação.
} 
do Brasil nos setores de maior valor agregado e intensivos em tecnologia relativa aos mercados mais dinâmicos.

Tabela 2 - Índice de Especialização das Exportações - Brasil versus Economias Selecionadas, 1999-2008

\begin{tabular}{|c|c|c|c|c|c|}
\hline Ano & Setor & APEX 23 & Argentina & China & EUA \\
\hline \multirow{6}{*}{ 1999-2002 } & Primário & 2,908 & nd & 4,243 & 3,703 \\
\hline & Rec. Naturais & 1,518 & nd & 2,838 & 2,633 \\
\hline & Baixa Tecg & 0,733 & nd & 0,288 & 0,938 \\
\hline & Média Tecg & 0,860 & nd & 1,240 & 0,725 \\
\hline & Alta Tecg & 0,478 & nd & 0,548 & 0,355 \\
\hline & Outros & 0,538 & nd & 3,913 & 0,488 \\
\hline \multirow{6}{*}{$2003-2006$} & Primário & 2,078 & nd & 5,478 & 3,283 \\
\hline & Rec. Naturais & 1,813 & nd & 3,435 & 2,063 \\
\hline & Baixa Tecg & 0,813 & nd & 0,410 & 1,070 \\
\hline & Média Tecg & 0,770 & nd & 0,673 & 0,648 \\
\hline & Alta Tecg & 0,478 & nd & 0,418 & 0,328 \\
\hline & Outros & 0,460 & nd & 4,268 & 0,425 \\
\hline \multirow{6}{*}{2007} & Primário & 3,670 & 0,610 & 11,120 & 3,420 \\
\hline & Rec. Naturais & 1,350 & 1,030 & 4,040 & 2,510 \\
\hline & Baixa Tecg & 0,760 & 1,550 & 0,420 & 1,010 \\
\hline & Média Tecg & 0,680 & 1,210 & 0,510 & 0,550 \\
\hline & Alta Tecg & 0,410 & 2,590 & 0,380 & 0,280 \\
\hline & Outros & 0,600 & 1,170 & 3,930 & 0,510 \\
\hline \multirow{6}{*}{2008} & Primário & 3,610 & 0,670 & 8,880 & 3,090 \\
\hline & Rec. Naturais & 1,220 & 1,050 & 3,340 & 2,050 \\
\hline & Baixa Tecg & 0,800 & 1,660 & 0,450 & 1,090 \\
\hline & Média Tecg & 0,780 & 1,020 & 0,800 & 0,530 \\
\hline & Alta Tecg & 0,340 & 3,170 & 0,200 & 0,300 \\
\hline & Outros & 0,630 & 0,950 & 4,930 & 0,470 \\
\hline
\end{tabular}

Nota: nd - não disponível.

Fonte: Elaboração própria com dados do FMI-Directions Trade Statistics a três dígitos. 
A diversificação das exportações é importante para países em desenvolvimento que, usualmente, dependem de poucos produtos exportáveis, em geral commodities, cujos preços tendem a oscilar fortemente em horizontes temporais mais longos. Isso expõe as economias mais dependentes de poucos produtos/setores comercializáveis. Para representar a diversificação das exportações se utilizará o índice de Herfindahl Hirschmann (IHH) ${ }^{10}$. De acordo com a literatura empírica, considera-se que a estrutura de exportações é concentrada quando o índice é maior do que 0,18 ; moderadamente concentrada quando está entre 0,10 e 0,18 ; e diversificada quando menor que 0,10 . Portanto, associado a esses intervalos é possível concluir sobre o grau de dependência da estrutura de exportação dos países aos preços de determinado produto.

A Tabela 3 reporta os resultados por agregação de intensidade tecnológica dos produtos, em que os indicadores em negrito e com área mais escura refletem elevada concentração; os de área destacada mais clara têm concentração moderada, e os sem área destacada apresentam baixa concentração (ou alta diversificação).

A tabela sugere que o Brasil apresenta uma pauta exportadora mais concentrada que a média dos países da amostra, especialmente em produtos de alta tecnologia e outros. Em baixa e média tecnologia, predominam indicadores de moderada concentração, ao passo que somente em manufaturas intensivas em recursos naturais o país apresentou elevada diversificação no período analisado. Tais resultados podem implicar, por um lado, que a crescente tendência de reprimarização da pauta ${ }^{11}$ coloca a possibilidade de instabilidade das receitas derivadas da volatilidade nos preços das commodities, além de abrir espaço para os problemas identificados na literatura como sendo a "maldição dos recursos naturais" (Sinnot, Nash e De La Torre, 2010), e por outro, que a maior concentração da pauta nos setores de maior intensidade tecnológica exponha a economia brasileira à riscos de acesso a mercados em um mundo pós-crise financeira global, em que a retomada do protecionismo em maior escala não pode ser descartada a priori.

\footnotetext{
${ }^{10}$ Este índice é calculado da seguinte forma:$$
I H H=\frac{\left(\sum_{J=1}^{n} p_{i}^{2}-\frac{1}{n}\right)}{1-\frac{1}{n}}
$$

Em que $p_{i}$ representa a participação das exportações do setor $i$ no total das exportações do país $j$, normalizado pelo número de observações. A soma dos quadrados das participações é o índice de Herfindahl; quando corrigido pelo número de observações, se transforma no IHH.

${ }^{11} \mathrm{O}$ Ministério da Fazenda (2011) reporta que, no final de 2010, 64,6\% das exportações brasileira são de commodities, ali classificados como o somatório de produtos básicos, semimanufaturados e 10 produtos manufaturados. 
Tabela 3 - Índice de Diversificação (ou Concentração) das Exportações - Brasil versus Economias Selecionadas, 1999-2008

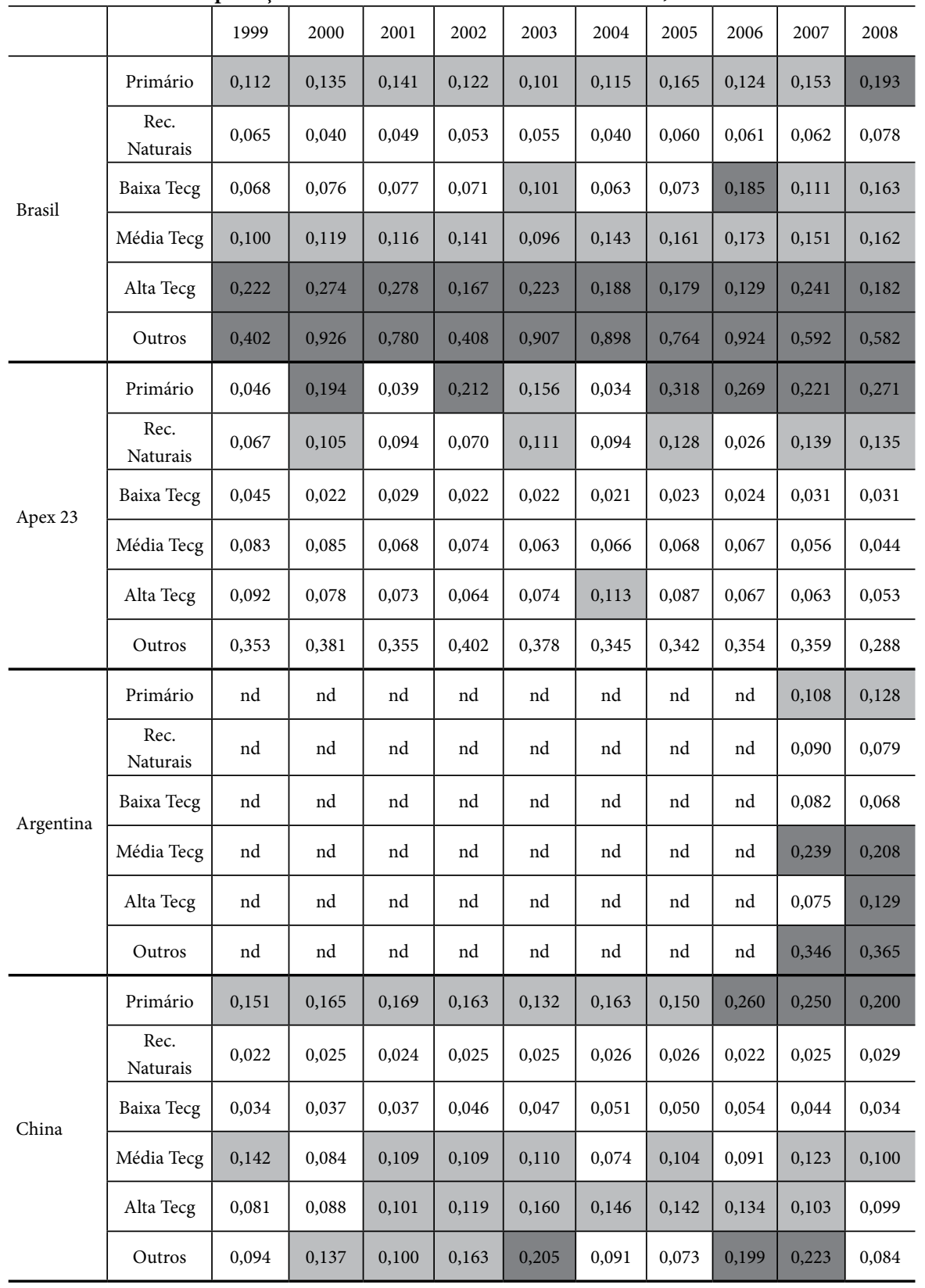


Tabela 3 - Índice de Diversificação (ou Concentração) das Exportações - Brasil versus Economias Selecionadas, 1999-2008 (Cont.)

\begin{tabular}{|c|c|c|c|c|c|c|c|c|c|c|c|}
\hline & & 1999 & 2000 & 2001 & 2002 & 2003 & 2004 & 2005 & 2006 & 2007 & 2008 \\
\hline \multirow{4}{*}{ EUA } & Primário & 0,041 & 0,041 & 0,040 & 0,047 & 0,045 & 0,052 & 0,054 & 0,062 & 0,068 & 0,095 \\
\hline & $\begin{array}{c}\text { Rec. } \\
\text { Naturais }\end{array}$ & 0,017 & 0,017 & 0,017 & 0,017 & 0,018 & 0,020 & 0,024 & 0,028 & 0,030 & 0,048 \\
\hline & Média Tecg & 0,051 & 0,051 & 0,047 & 0,046 & 0,043 & 0,041 & 0,040 & 0,039 & 0,036 & 0,033 \\
\hline & Alta Tecg & 0,065 & 0,762 & 0,053 & 0,051 & 0,049 & 0,045 & 0,044 & 0,046 & 0,042 & 0,043 \\
\hline
\end{tabular}

Nota: nd - não disponível.

Fonte: Elaboração própria com dados do FMI-Directions Trade Statistics a três dígitos.

Por seu turno, o índice de similaridade de exportações permite vislumbrar os padrões de comércio em cada país de forma comparativa. Ele varia entre zero (0), indicando completa diferença entre as estruturas de exportação, e 100, similaridade perfeita. Assim:

$$
I S X i, p=\operatorname{sum}\left[\min (X p i, X p j)^{\star} 100\right]
$$

Onde:

$X p i$ e Xpj são, respectivamente, a parcela das exportações do "setor $p$ " originadas nos países “ $i$ " “ $j$ ".

Esse indicador revela concorrência entre as estruturas de exportação dos países considerados, i.e., se o índice é igual à zero, as estruturas de exportação são diferentes, portanto, não existe concorrência entre produtos ou setores industriais. No entanto, quanto maior é o valor do indicador ou quanto mais próximo de 100, maior é o grau de concorrência comercial. 
Tabela 4 - Î́ndice de Similaridade das Exportações - Brasil versus Economias Selecionadas, 1999-2008

\begin{tabular}{l|c|c|c|c|c|c|c|c|c|c}
\hline & 1999 & 2000 & 2001 & 2002 & 2003 & 2004 & 2005 & 2006 & 2007 & 2008 \\
\hline APEX-23 & 52,10 & 53,40 & 55,69 & 55,41 & 54,54 & 52,86 & 53,72 & 54,84 & 56,45 & 55,22 \\
\hline Argentina & nd & nd & nd & nd & nd & nd & nd & nd & 52,61 & 51,42 \\
\hline China & 31,98 & 34,93 & 36,18 & 34,95 & 33,96 & 34,09 & 34,37 & 34,04 & 33,41 & 32,74 \\
\hline EUA & 50,40 & 54,51 & 55,22 & 52,01 & 51,25 & 51,38 & 52,68 & 51,99 & 53,04 & 50,95 \\
\hline
\end{tabular}

Nota: nd - não disponível.

Fonte: Elaboração própria com dados do FMI-Directions Trade Statistics a três dígitos.

Os resultados da Tabela 4 indicam que o Brasil possui um índice de similaridade de exportações bastante elevado a respeito do total da amostra (APEX-23), o que indicaria um nível de concorrência significativo entre a estrutura das exportações brasileiras e a dos países aqui citados. Os países que se configurariam como os mais importantes competidores comerciais do Brasil seriam a Argentina, Coreia do Sul, Turquia, Venezuela, Canadá, México, Estados Unidos, África do Sul, Índia e Polônia. No caso da China, tal similaridade é menor. Esses mesmos resultados são observados quando o índice é calculado por setores intensivos em tecnologia, com destaque para o setor de média tecnologia, ao qual pertence o setor de transportes, em que se observa um maior nível de concorrência com os países desenvolvidos da amostra e com os países asiáticos $^{12}$.

O índice de complementaridade de comércio é bastante utilizado para avaliar processos de integração econômica, na medida em que procura evidenciar em que grau as estruturas de exportações e importações coincidem. Um índice de zero (0) indica que não há exportações e importações entre os países, e um índice de cem (100) sugere perfeita similaridade nas respectivas estruturas de comércio exterior. Assim:

$$
\operatorname{ICCij}=100-\operatorname{sum}(|m i k-x i j| / 2)
$$

Onde:

xij representa a parcela das exportações do produto/setor " $i$ " nas exportações totais do "país j"; e mik é a parcela das importações do produto/setor " $i$ " total importado pelo "país".

\footnotetext{
${ }^{12}$ Por falta de espaço apresentamos somente alguns resultados. Os detalhes podem ser disponibilizados mediante solicitação.
} 
O ICC analisa o padrão exportador de um país relativo ao perfil importador de um parceiro comercial ou de um grupo de países, i.e., mede a semelhança entre o padrão de oferta de uma economia com o de demanda de outra. Revela, assim, o potencial de crescimento do comércio internacional. Em processos de integração, quanto maior esse indicador, maior são as possibilidades de sucesso, porque maiores são os crescimentos esperados dos fluxos de comércio.

Tabela 5 - Índice de Complementaridade de Comércio - Brasil versus Economias Selecionadas, 1999-2008

\begin{tabular}{l|c|c|c|c|c|c|c|c|c|c}
\hline & 1999 & 2000 & 2001 & 2002 & 2003 & 2004 & 2005 & 2006 & 2007 & 2008 \\
\hline APEX-23 & 48,84 & 51,08 & 52,69 & 52,49 & 52,1 & 52,56 & 55,20 & 56,26 & 55,72 & 54,63 \\
\hline Argentina & 50,08 & 51,41 & 51,38 & 49,34 & 49,65 & 50,40 & 52,35 & 51,28 & 48,83 & 47,93 \\
\hline China & 43,53 & 44,79 & 46,27 & 44,62 & 46,05 & 44,23 & 45,39 & 45,95 & 46,35 & 48,62 \\
\hline EUA & 46,07 & 47,68 & 49,50 & 49,59 & 49,14 & 48,84 & 52,04 & 52,68 & 51,06 & 49,55 \\
\hline
\end{tabular}

Fonte: Elaboração própria com dados do FMI-Directions Trade Statistics a três dígitos.

No caso aqui estudado, o índice de complementaridade comercial do Brasil com os países da amostra é bastante elevado, como também revela o indicador de similaridade de exportações, quer dizer, em torno de 50. Portanto, os países selecionados apresentam um considerável potencial de crescimento do comércio internacional com o Brasil, destacando-se Turquia, Chile, Canadá, Egito, Polônia e África do Sul. Por outro lado, quando se analisa por setores intensivos em tecnologia, destaca-se outra vez o setor de intensidade média, por conta do setor de transporte, como o de maior potencial de crescimento de comércio intraindustrial e de sucesso em acordos comerciais. No caso da China, o índice cresceu de 43,5\% em 1999 para 48,6\% em $2008^{13}$.

\subsection{AVALIANDO O GRAU DE CONVERGÊNCIA DOS CICLOS E SUAS RELAÇÕES COM O COMÉRCIO}

A subseção anterior procurou caracterizar o padrão recente de inserção comercial externa do Brasil, enfatizando o período 1999-2008 e tendo por referência o debate em torno dos efeitos da ascensão chinesa. Uma questão pendente é se a economia brasileira tende ou não a apresentar uma maior convergência cíclica com o gigante asiático, em função da própria complementaridade entre a dinâmica de crescimento intensiva na demanda de recursos naturais da China e a abundância de tais fatores no Brasil.

\footnotetext{
${ }^{13}$ Por falta de espaço apresentamos somente alguns resultados. Os detalhes podem ser disponibilizados mediante solicitação.
} 
Verificou-se, por meio da análise de diversos indicadores de desempenho comercial, que, de fato, há uma intensificação do comércio bilateral Brasil-China e que, conforme sugere a literatura, essa relação tende a posicionar a economia brasileira como especializada no fornecimento de commodities. Tendo tais resultados como pano de fundo, procura-se avançar aqui na identificação da existência (ou não) de um padrão de maior convergência cíclica entre Brasil e China e se tal dinâmica está (ou não) relacionada com o comércio internacional, reforçando a especialização antes identificada.

A análise de convergência de ciclos econômicos entre o Brasil e China tem como referência os estudos de Frenkel e Rose (1998), seminal na análise da relação entre ciclos econômicos e integração comercial, e de Calderón (2008), que realiza uma pesquisa semelhante, ampliando a análise empírica para incluir países desenvolvidos e em desenvolvimento. Ambos os artigos estudam a correlação de ciclos econômicos entre grupos de países, através de várias metodologias de estimação de ciclos e, além disso, avaliam os determinantes da evolução de um indicador de convergência ou divergência entre diferentes economias através de algumas medidas de intensidade de comércio internacional.

O comércio internacional cresceu aceleradamente nos últimos 25 anos, inclusive a uma velocidade maior que o PIB da economia global. São vários os autores que têm estudado as explicações para esse forte crescimento do comércio internacional, com destaque especial para Frankel e Rose (1998) e Calderón (2008). Essa literatura destaca que os principais determinantes da evolução positiva das transações internacionais de bens e serviços são: a proliferação e aprofundamento dos acordos de integração comercial; os processos de reformas estruturais que incluíam a abertura comercial mediante a redução de barreiras comerciais tarifárias e não tarifárias; a ascensão dos países emergentes, especialmente dos chamados BRICs (Brasil, Rússia, China e Índia), como grandes traders; o ciclo de crescimento acelerados dos países desenvolvidos, especialmente dos Estados Unidos (EUA), que forma o principal mercado demandante; também se destaca o agressivo trabalho de promoção comercial de alguns países emergentes, como o caso do Brasil, derivado tanto da assinatura de novos acordos comerciais, como das atuações junto a OMC.

Esse forte crescimento dos fluxos comerciais está aumentando os canais de transmissão de impulsos econômicos entre os países, gerando uma maior sincronia de ciclos econômicos. Frankel e Rose (1998), Calderón et al. (2007), Shing e Wang (2004), Rana (2007), dentre outros, oferecem evidências empíricas de que a maior intensidade das relações comerciais aumenta a correlação de ciclos entre os países. De acordo com essa literatura, no entanto, o efeito do comércio sobre a correlação de ciclos econômicos não é inequívoca, dependendo do dinamismo do fluxo comercial e, especialmente, do tipo de comércio que se desenvolve entre os países. Nesse sentido, Shin e 
Wang (2004) destacam que os canais através dos quais se propagam os impulsos do comércio ao crescimento econômico dos países são: (i) o comércio interindústria, (ii) o comércio intraindústria, (iii) spillovers de demanda, e (iv) a coordenação política. Nesse sentido, se o tipo de choque comercial que predomina entre os países é derivado de um choque de demanda, pode-se esperar um aumento da correlação dos ciclos econômicos entre os países considerados. Um choque positivo em um país pode provocar um aumento da demanda de importação e, consequentemente, levar a um efeito spillover de demanda, produzindo crescimento econômico mútuo. O grau desse impacto dependerá do nível de integração comercial das economias ou de interdependência econômica ou, ainda, da intensidade de comércio.

No entanto, se o choque dominante é do tipo indústria-específico, i.e., ocorre exclusivamente em determinado setor de atividade econômica, o efeito sobre o ciclo econômico pode ser negativo, dado que pode levar a uma especialização produtiva e, portanto a uma especialização comercial. A relação comercial derivada será do tipo Heckscher-Ohlin e/ou Ricardiana, de forma que o comércio será interindustrial, resultado da especialização produtiva. Se a relação de comércio é do tipo interindustrial, a convergência de ciclos econômicos pode ser negativa. Por outro lado, se o comércio é predominantemente intraindustrial, como é o caso dos países desenvolvidos, o efeito do crescimento do comércio sobre a correlação de ciclos econômicos não necessariamente leva a efeitos assimétricos, já que o padrão de especialização é industrial; pelo contrário, pode levar a uma maior convergência de ciclos. Como destaca Calderon et al. (2007), o efeito do comércio sobre a convergência de ciclos econômicos é ambíguo e depende do tipo de choque comercial e da estrutura de comércio entre os países, e portanto, só uma análise empírica pode buscar evidências mais claras sobre as relações subjacentes ao fenômeno em questão.

Frankel e Rose (1998) são os primeiros a analisar a relação entre intensidade comercial e correlação de ciclos econômicos, utilizando uma amostra de 21 países industrializados. A hipótese inicial é que existe uma endogeneidade nessa relação, de forma que existiria uma variável que determinaria, ao mesmo tempo, intensidade de comércio e ciclos, como por exemplo, a união monetária. Nesse sentido, a análise econométrica deve considerar esse inconveniente para evitar utilizar estimadores viesados e não eficientes. Para tanto os autores utilizam um modelo com variável instrumental (VI), sendo que os instrumentos são as variáveis de uma equação gravitacional tradicional, i.e., distância, fronteira e língua. O resultado das estimações desses autores mostra uma relação positiva entre intensidade de comércio e ciclos econômicos. Esse estudo serviu como base para uma série de trabalhos posteriores que analisam a relação entre comércio e ciclo para diferentes áreas geográficas, como em Calderón et al. (2007), Shing e Wang (2004) e Rana (2007), que inspiraram o exercício apresentado na sequência. 
Reproduz-se aqui a estratégia metodológica original utilizada por Frankel e Rose (1998). Para calcular a correlação dos ciclos econômicos foram utilizadas duas metodologias alternativas de estimação dos ciclos, a de Hodrick-Prescott (HP) e a de Baxter e King $(\mathrm{BK})^{14}$. Os dados de PIB para o período 1960-2007 estão em preços constantes na moeda local e foram transformados em logaritmos naturais, como sugerido por Calderón (2008) Também se utilizou como alternativa o produto industrial. A fonte original dos dados é o World Development Indicators (WDI) do Banco Mundial. Com os ciclos estimados para cada um dos filtros anteriores, i.e., HP e BK, foram calculados os coeficientes de correlação para cada par de países, sempre tomando o Brasil como referência. Além disso, para contextualizar a importância chinesa foi considerado um conjunto de 23 países escolhidos como mercados prioritários para as ações de promoção comercial da APEX-Brasil. Conforme destacado na subseção 3.1, constata-se que no período analisado houve uma nítida tendência de ampliação da intensidade de comércio entre Brasil e China. Por sua vez, ao se calcular os indicadores de convergência de produto (Gráfico 3, no Apêndice) sugerem que a dinâmica de expansão da economia brasileira está mais associada à dinâmica chinesa, e menos vinculada com EUA e Argentina ${ }^{15}$.

Após calcular os coeficientes de correlação, cujos resultados para a China, EUA e Argentina foram destacados no Gráfico 3 (Apêndice), estimou-se a intensidade de comércio bilateral entre o Brasil e um país $j$, no tempo $t$, a partir de duas proxys propostas por Frenkel e Rose (1998). A primeira baseia-se exclusivamente nos dados de comércio internacional:

$$
I T C_{i j t}=\left(X_{i j t}+M_{i j t}\right) /\left(X_{i t}+X_{j t}+M_{i t}+M_{j t}\right)
$$

Onde:

$X_{i j t}$ refere-se às exportações do país $i$ para o país $j$, durante o período $t ; X_{i t}$ e $M_{i t}$ referem-se as exportações e as importações totais do país $i$. Portanto, esse indicador de intensidade de comércio pondera em relação ao comércio total.

A segunda proxy pondera o comércio bilateral total pelo PIB dos dois países:

$$
I T Y_{i j t}=\left(X_{i j t}+M_{i j t}\right) /\left(Y_{i t}+Y_{j t}\right)
$$

\footnotetext{
${ }^{14}$ Baxter e King (1999).

${ }^{15}$ Considerando os resultados para o conjunto de 23 países destacados na nota anterior é possível concluir que o de convergência de ciclos está crescendo entre o Brasil e os países asiáticos, incluindo Cingapura e a África do Sul; é estável e relativamente elevado com o Chile, Peru, Colômbia, Noruega, Estados Unidos e Canadá; e é decrescente com a Argentina, México e Venezuela.
} 
em que $Y_{i t}$ é o nível do PIB nominal do país $i$ no período $t$. Os dados do comércio bilateral são do FMI, do Direction of Trade Statistics, e o PIB são do WDI-Banco Mundial. Posteriormente estima-se a relação entre convergência de ciclos e intensidade de comércio utilizando como base o modelo de Frenkel e Rose (1998), i.e.:

$$
\operatorname{Corr}(v, s)_{i j t}=\alpha+\beta I T_{i j t}+\varepsilon_{i j t}
$$

Em que $\operatorname{Corr}(v, s)_{i j t}$ denota a correlação de ciclos econômicos entre o país $i$ e $j$, no tempo $t$ para a proxy de atividade econômica $v$, que no nosso caso corresponde ao PIB real e a produção industrial, calculada pelo filtros, que indica uma das metodologias alternativas de estimação dos ciclos, de Hodrick-Prescott (HP) ou de Baxter e King (BK). IT refere-se à intensidade comercial, que pode assumir a forma correspondente às equações (6) ou (7). Finalmente $\alpha$ e $\beta$ são os coeficientes da regressão a serem estimados. Foram estimadas oito versões diferentes do modelo derivados das duas definições de ciclos, dos dois indicadores de atividade econômica e das duas medidas de intensidade comercial. Seguindo a metodologia de Frankel e Rose (1998), Calderón et al. (2007) e Calderón (2008), a equação (8) foi estimada tomando três períodos independentes, mas empilhados: 1962-1977, 1978-1993 e 1994-2007. Todos os 23 países da amostra são utilizados no pool de dados, com exceção de Cuba, Rússia, Polônia e Vietnã, por causa da falta de dados.

De acordo com a teoria, o valor e o sinal de $\beta$ revelarão como o comércio está afetando a convergência dos ciclos econômicos entre os países estratégicos e o Brasil. Se $\beta$ é negativo, indicaria que o efeito especialização industrial é o que domina nas transações comerciais e, portanto, uma maior independência entre as economias. Por outro lado, se $\beta$ é positivo, o efeito intraindústria seria o dominante nas relações comerciais, o que acabaria gerando uma maior correlação de ciclos entre os países. $\mathrm{O}$ valor de $\beta$, como esperado, reflete a importância do fenômeno.

Para evitar os problemas derivados de uma estimação viesada, por causa da mais que provável endogeneidade entre atividade econômica e comércio, utiliza-se um modelo com variável instrumental, como Frankel e Rose (1998), Calderón et al. (2007) e Calderón (2008). Portanto, é necessário encontrar os determinantes da intensidade de comércio para utilizar como variáveis instrumentais. Esse trabalho reproduz a estratégia utilizada por Frankel e Rose (1998) e utiliza como determinantes da intensidade de comércio bilateral uma equação gravitacional simples, sendo as variáveis independentes a distância, a língua e a fronteira.

As evidências empíricas derivadas da estimação do modelo gravitacional são apresentadas na Tabela 6. A distância (medida em logaritmo natural) mostra uma relação negativa e estatisticamente significativa com a intensidade de comércio, com um nível semelhante em qualquer uma das duas ponderações (TT, ponderado pelo 
comércio total; TY, ponderado pelo PIB). Isso revela que a distância, como esperado pela teoria, introduz desvantagens comparativas por causa dos custos de transporte. No entanto, as dummys de língua e fronteira não se mostraram estatisticamente significativas. Como no caso do estudo de Frenkel e Rose (1998), a equação que ponderada pelo comércio total apresenta melhores resultados que a ponderada pelo PIB. Os testes estatísticos ${ }^{16}$ mostram que a estimação por MQO é eficiente e consistente, sendo, portanto, melhor do que os modelos de dados de painel por Efeitos Fixos e/ou Aleatórios (se aceita a hipótese nula de que o MQO é eficiente e consistente).

Os coeficientes estimados ( $\beta$, através de variável instrumental) da intensidade de comércio sobre a correlação de ciclos econômicos entre o Brasil e os países estratégicos são apresentados na Tabela 7. Oito versões diferentes da equação (8) foram estimadas, de acordo com as diferentes proxys de intensidade de comércio, de atividade econômica e de tipo de filtro para calcular os ciclos econômicos ${ }^{17}$.

Tabela 6 - Resultados do Modelo Gravitacional

\begin{tabular}{l|c|c}
\hline & TT & TY \\
\hline Fronteira & $-0,3325$ & $-0,6717$ \\
\hline Língua & $(1,015)$ & $(1,0473)$ \\
\hline & $-0,9941$ & $-1,1534$ \\
\hline Distância & $(1,3672)$ & $(1,4107)$ \\
\hline & $-1,8588^{* * *}$ & $-1,8679^{* * *}$ \\
\hline Constante & $(0,6182)$ & $(0,6379)$ \\
\hline & $10,7173^{*}$ & 9,2630 \\
\hline $\mathrm{R}-$ ajustado & $(5,7121)$ & $(5,8940)$ \\
\hline $\mathrm{N}$ & & 0,14 \\
\hline $\mathrm{F}$ & & 57 \\
\hline $\mathrm{N}$ & & 4,1501 \\
\hline
\end{tabular}

Nota: ${ }^{(*)} p<0,05,{ }^{(*)} p<0,01,{ }^{(* * *)} p<0,001$. Os dados são incompletos para Cuba, Angola, Polônia, Rússia e Vietnã.

Desvio-padrão entre parênteses. TT: Intensidade de comércio ponderado pelo comércio total; TY: Intensidade de comércio ponderado pelo PIB.

Fonte: Elaboração própria com base nos resultados da pesquisa.

\footnotetext{
${ }^{16}$ Por uma questão de espaço eles foram omitidos aqui, mas podem ser disponibilizados aos interessados.

${ }^{17}$ Os resultados das estimações não são apresentados aqui, por limitação de espaço, estando disponíveis mediante solicitação. Eles mostram, em todos os casos, que o modelo com variável instrumental é consistente e eficiente e que, além disso, os instrumentos utilizados são válidos e estatisticamente consistentes.
} 
Tabela 7 - Coeficientes Estimados de $\beta$ por VI. Efeitos da Intensidade de Comércio sobre a Correlação de Ciclos

\begin{tabular}{l|c|c|c}
\hline & Filtro & TT & TY \\
\hline PIB & BK & 6,00 & 6,00 \\
\hline & & $(5,22)$ & $(5,72)$ \\
\hline Produto industrial & BK & 4,63 & 4,18 \\
\hline & & $(5,59)$ & $(6,18)$ \\
\hline PIB & HP & 6,88 & 5,56 \\
\hline & & $(7,09)$ & $(7,85)$ \\
\hline Produto industrial & HP & 3,99 & 2,57 \\
\hline & & $(6,47)$ & $(7,24)$ \\
\hline
\end{tabular}

Nota: ${ }^{(*)} p<0,05,{ }^{(* *)} p<0,01,{ }^{(* * *)} p<0,001$. Os dados são incompletos para Cuba, Angola, Polônia, Rússia e Vietnã.

$\beta$ estimado por VI multiplicado por 100.

Desvio-padrão entre parêntesis. TT: Intensidade de comércio ponderado pelo comércio total; TY: Intensidade de comércio ponderado pelo PIB; BK: Baxter-King; HP: Hodrick-Prescott.

Fonte: Elaboração própria com base nos resultados da pesquisa.

Os $\beta$ estimados, em todos os casos, são positivos, o que significaria que quanto maior a intensidade de comércio, maior também a convergência de ciclos econômicos entre o Brasil e os países da amostra. No entanto, o efeito da intensidade de comércio mostra-se estatisticamente pouco significativo, o que sugere cautela na análise das implicações em termos de padrões de especialização. Os resultados dos indicadores de comércio obtidos na subseção 3.1 indicariam a especialização e menor diversificação exportadora. Além disso, encontram-se diferenças relativamente importantes nas estimações de $\beta$ entre as equações que utilizam como variável dependente a correlação de ciclos do PIB e as que utilizam a produção industrial. No entanto, as diferenças entre as metodologias de filtro dos ciclos são mínimas. Para exemplificar uma interpretação econômica dos resultados das estimações da relação entre comércio e ciclo, considere o $\beta$ estimado no modelo de correlação de ciclos de PIB (filtrado por BK) explicado por intensidade de comércio ponderado pelo comércio total. Um crescimento da intensidade de comércio por um valor equivalente a um desvio-padrão aumentaria a correlação de ciclos de 0,53 a $0,61(=0,53$ $+0,06^{\star} 1,32$ ). Assim, para o caso específico das relações entre Brasil e China, a intensificação do comércio bilateral parece estar contribuindo para a tendência de maior convergência cíclica observada no Gráfico 3 (Apêndice). 


\section{CONSIDERAÇÕES FINAIS}

A ascensão da China à condição de potência econômica global já é uma realidade que interage decisivamente com as perspectivas da economia brasileira. Desde meados de 2004 o Brasil vem experimentando um processo singular de desempenho quando se toma em perspectiva a trajetória de desenvolvimento do período do pós-Segunda Grande Guerra. A aceleração do crescimento econômico veio acompanhada de inflação moderada, de melhorias nas contas públicas e na solvência externa e na importante incorporação das classes baixas na dinâmica de consumo, com a verificação de uma tendência de redução nas desigualdades distributivas. Nem mesmo a crise financeira global agravada desde 2008 foi capaz de colocar em xeque esse bom momento, ainda que o retorno dos déficits em conta corrente, as pressões inflacionárias, a insuficiência na infraestrutura física e institucional do país, dentre outras questões, sinalizem para a existência de obstáculos não desprezíveis para a consolidação de uma dinâmica mais robusta de crescimento com inclusão social.

A experiência brasileira recente guarda similaridade com a de outros países que se caracterizam por produzirem e exportarem recursos naturais, cuja demanda tem sido potencializada significativamente pelo processo de rápida urbanização e industrialização de potências emergentes, especialmente a China. É bem verdade que não se pode atribuir a esse fato em particular a melhoria do desempenho macroeconômico recente, bem como de seus desdobramentos na esfera social. Nem mesmo parece ser razoável, para o caso brasileiro, atribuir ao boom das exportações de commodities um status superior no rol dos determinantes da aceleração do crescimento do país, que parece estar mais bem assentado no fortalecimento do seu mercado interno. Os aumentos reais no salário mínimo, os programas de transferência de renda, o aumento na criação de emprego e os ganhos reais nos rendimentos do trabalho, a expansão do crédito, dentre outros, parecem estar contribuindo decisivamente para o ciclo recente de crescimento no consumo e nos investimentos.

Todavia, não se pode perder de vista que o ciclo global de crescimento elevado com baixa inflação entre 2003 e 2008 permitiu com que velhos entraves ao nosso desenvolvimento, especialmente nas esferas fiscal e externa, fossem mitigados. E tal ciclo esteve intrinsecamente vinculado à ascensão chinesa. A China também se recuperou rapidamente da crise financeira global e agora retoma os velhos dilemas gerados pelo crescimento excessivamente rápido desses anos 2000: pressões inflacionárias, ameaças de protecionismo de importantes parceiros comerciais, como os EUA, degradação do meio ambiente, dentre outros. Os imperativos do crescimento, para absorver a população que ainda cresce e, mais importante, que se urbaniza ao 
ritmo alucinante de uma cidade de São Paulo por ano, e da manutenção da ordem sobre o estrito controle do Partido Comunista - a despeito da ideologia em si perder espaço como amálgama e fonte de legitimidade de poder do governo central - levam a China para aprofundar seu processo de internacionalização. Recursos naturais e acesso a novos mercados são dois vetores desse mesmo processo.

Nesse contexto é que o presente trabalho procurou destacar alguns dos efeitos sobre o Brasil da ascensão da China à condição de potência econômica global. Privilegiou-se a dimensão do comércio internacional. Essa e outras facetas das relações bilaterais entre essas duas nações têm sido alvo de grande atenção por parte de especialistas em diversos campos do conhecimento, aqui divididos entre "otimistas" e “pessimistas”. Não se pretendeu equacionar tão complexo debate. Ainda assim, nossos resultados sinalizam para o fato de que o Brasil representa a experiência média sul-americana e de várias outras economias ricas em recursos naturais na África e Ásia, beneficiadas pela demanda chinesa por matérias-primas. Essa gerou um ciclo de expansão nos preços desses produtos, o que por sua vez criou um ambiente propício à aceleração no crescimento com melhoria na situação fiscal e externa das economias com o perfil de complementaridade à China. Verificou-se a importância crescente desse país enquanto destino de exportações e origem de importações do Brasil e do restante da América Latina.

Por outro lado, essa complementaridade tem gerado um perfil de comércio que aprofunda a tendência histórica de especialização na produção e exportação de produtos intensivos na utilização de recursos naturais, e de importações de manufaturas intensivas em tecnologia. Nesse momento de ascensão chinesa, a maior convergência cíclica entre a economia brasileira e a do gigante asiático, associada a uma menor convergência com os EUA e as principais economias sul-americanas, particularmente a Argentina, sugere um realinhamento na dinâmica de crescimento do país. As evidências aqui apresentadas não permitem afirmar que tal efeito-China seria (ou será) a fonte de expansão da economia brasileira, apenas indicam que não se pode descartar a possibilidade de haver uma maior convergência cíclica originada, dentre outros fatores, pela maior intensidade das relações comerciais bilaterais.

Os indicadores de padrão e competitividade do comércio exterior reforçam a percepção de que o comércio bilateral Brasil-China, quando controlado para o padrão verificado na amostra aqui utilizada, tende a ser ainda mais marcado pela especialização em setores intensivos em recursos naturais. Enquanto a dinâmica chinesa de expansão viabilizar o ciclo de expansão de preços e quantidades vendidas desses produtos, a economia brasileira poderá ter vantagens de posicionamento. Todavia, 
há riscos importantes em tal especialização que, mesmo não tendo sido explorados neste trabalho, ecoam na velha discussão de sustentabilidade de um padrão de desenvolvimento assentado na produção e exportação de commodities.

Nesse sentido, as evidências apresentadas nas seções 3.1 e 3.2 se complementam e formam um quadro de referência que permite contribuir para o debate proposto pela literatura destacada na Introdução. Todavia, há que se ressaltar que os resultados aqui apresentados devem ser complementados por novos estudos que ampliem a amostra de países trabalhados, aprofundem suas interpretações e explorem outras dimensões dos fenômenos em curso. Em especial, parece ser importante avaliar a falta de sincronia entre a velocidade das transformações produzidas pela ascensão chinesa e a capacidade das lideranças brasileiras, nos setores público e privado, em formular estratégias em longo prazo.

A experiência chinesa recente nos relembra o quão importante é o estabelecimento dessa sintonia estratégica entre as visões em longo prazo sobre o processo de desenvolvimento de uma nação - que, necessariamente, se constrói na esfera pública e com a participação ativa do Estado - e a atuação de seus atores em particular (empresas, setores econômicos, e agentes diversos), que atuam na esfera privada e são movidos por interesses mais imediatos. Para se retomar o que parece já ter se tornado um chavão, a China parece saber o que quer do Brasil, ao passo que esse não sabe muito bem o que quer do gigante asiático. Se a resposta for "queremos mercados para commodities e a importação de manufaturas com boa qualidade e preços em queda", o Brasil estará abdicando de importantes graus de liberdade em seu próprio processo de desenvolvimento. Todavia, se a resposta for "queremos construir uma ponte sólida entre essas duas forças em ascensão, que se baseie no direito mútuo a um processo de desenvolvimento robusto e sustentando por estruturas de produção e de comércio internacional diversificadas", há muito que se construir politicamente. Os interesses mercantis locais, a força gravitacional das vantagens competitivas em recursos naturais e o ativismo chinês na busca de seus legítimos interesses podem empurrar o Brasil alguns degraus para baixo na escada que o país vem galgando desde os anos 1930 para tentar superar o subdesenvolvimento e o status de economia periférica. 


\section{APÊNDICE}

\section{Gráfico 1 - Comércio de mercadorias entre Brasil e China,} 1988-2009 (US\$ milhões)
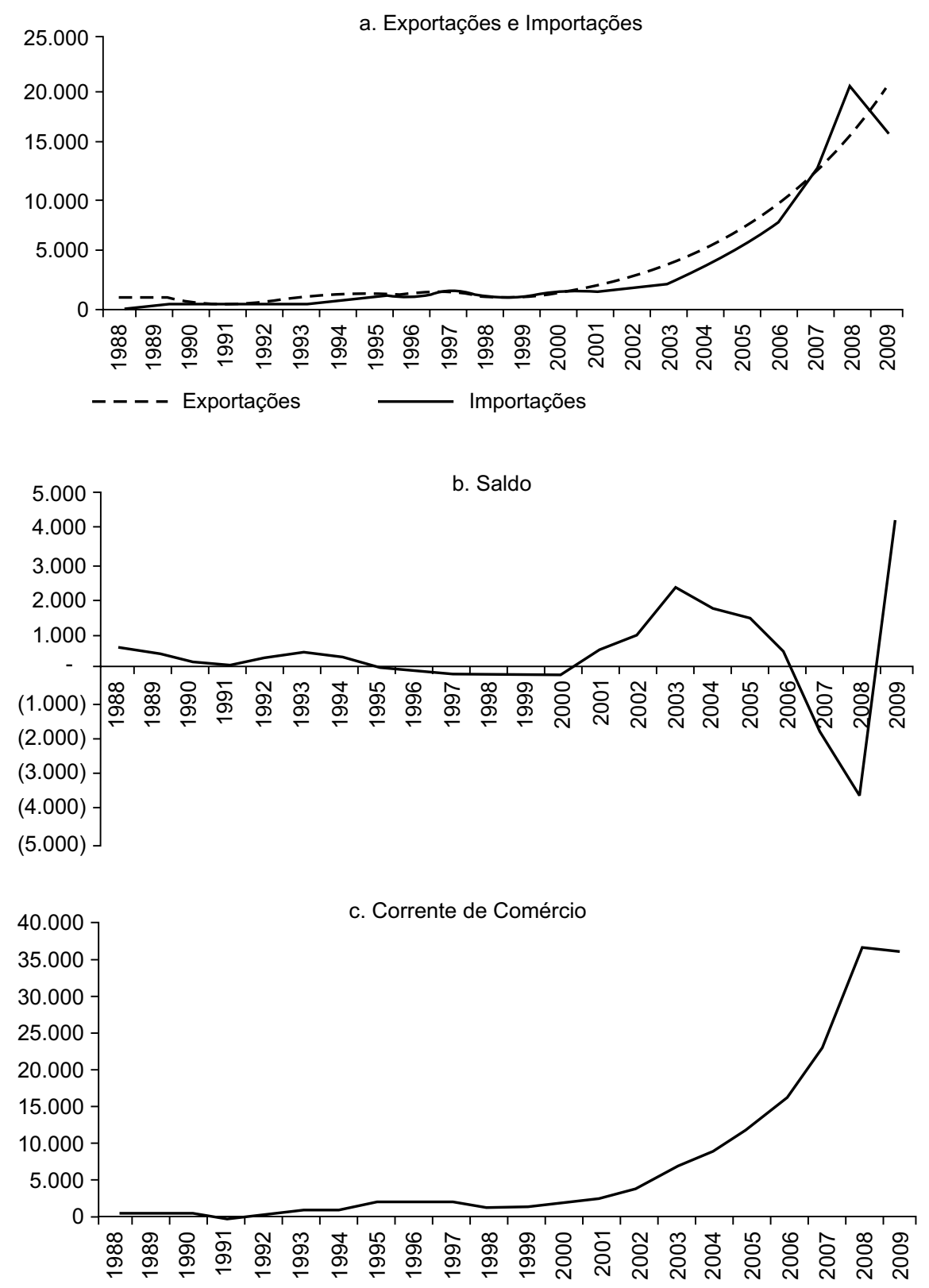

Fonte: Elaboração própria com base em dados do MDIC. 


\section{Gráfico 2 - Comércio de mercadorias entre Brasil e China por intensidade tecnológica*, 1990-2008 (\% do total exportado)}
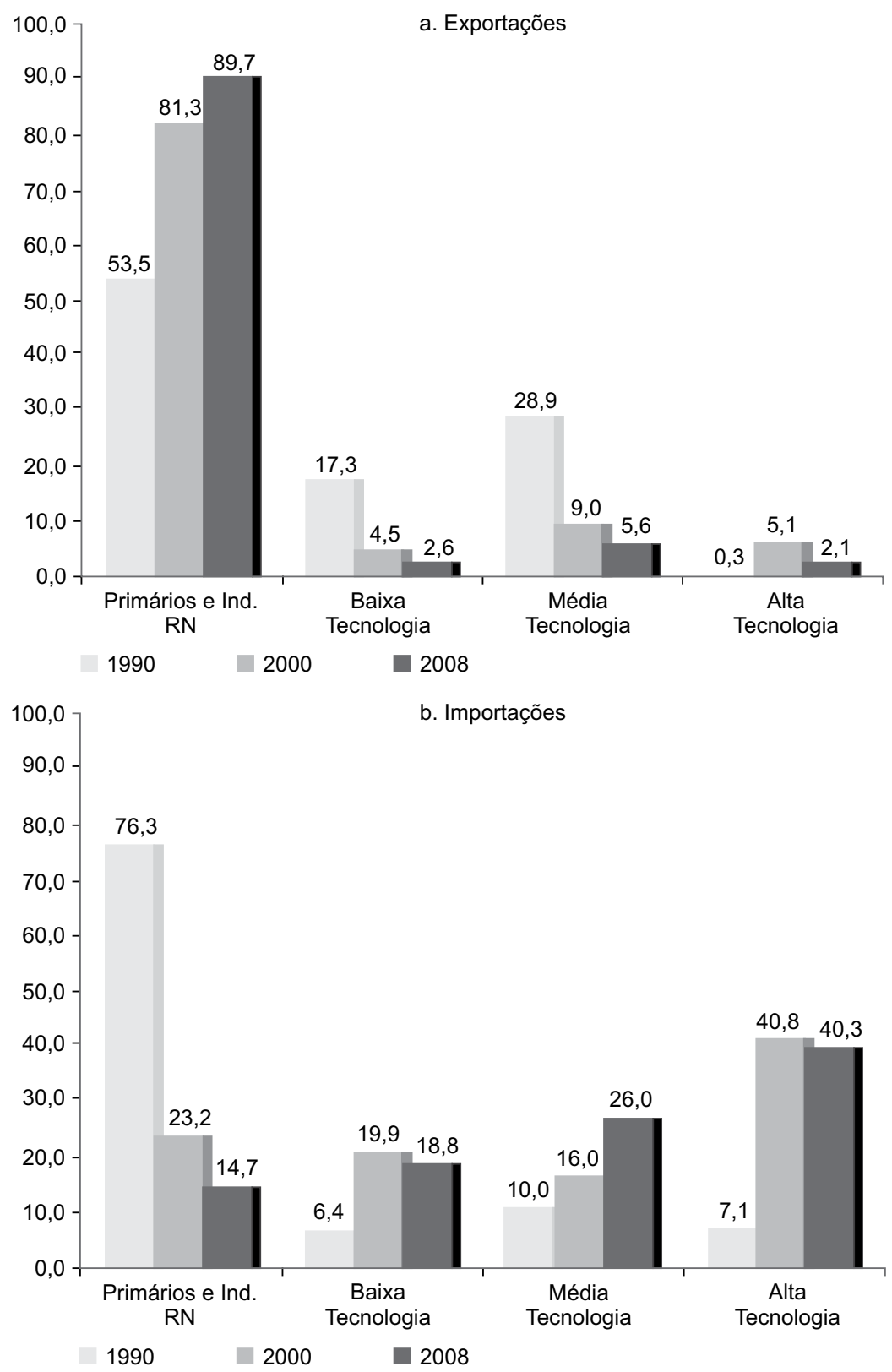

Nota: ${ }^{*}$ A classificação dos setores está disponível na fonte dos dados.

Fonte: elaboração própria com dados de CEPAL. Panorama de la inserción internacional de América Latina y El Caribe 2008-2009. Disponível em: http://www.cepal.org/Comercio/paninsal/Anexo2008_2009/espanol/portada.htm. Acesso em 16/01/2012. 


\section{Gráfico 3 - Correlação entre PIBs de economias selecionadas pelos métodos Baster-King e Hodrick-Prescott, 1960-2007* (\%)}
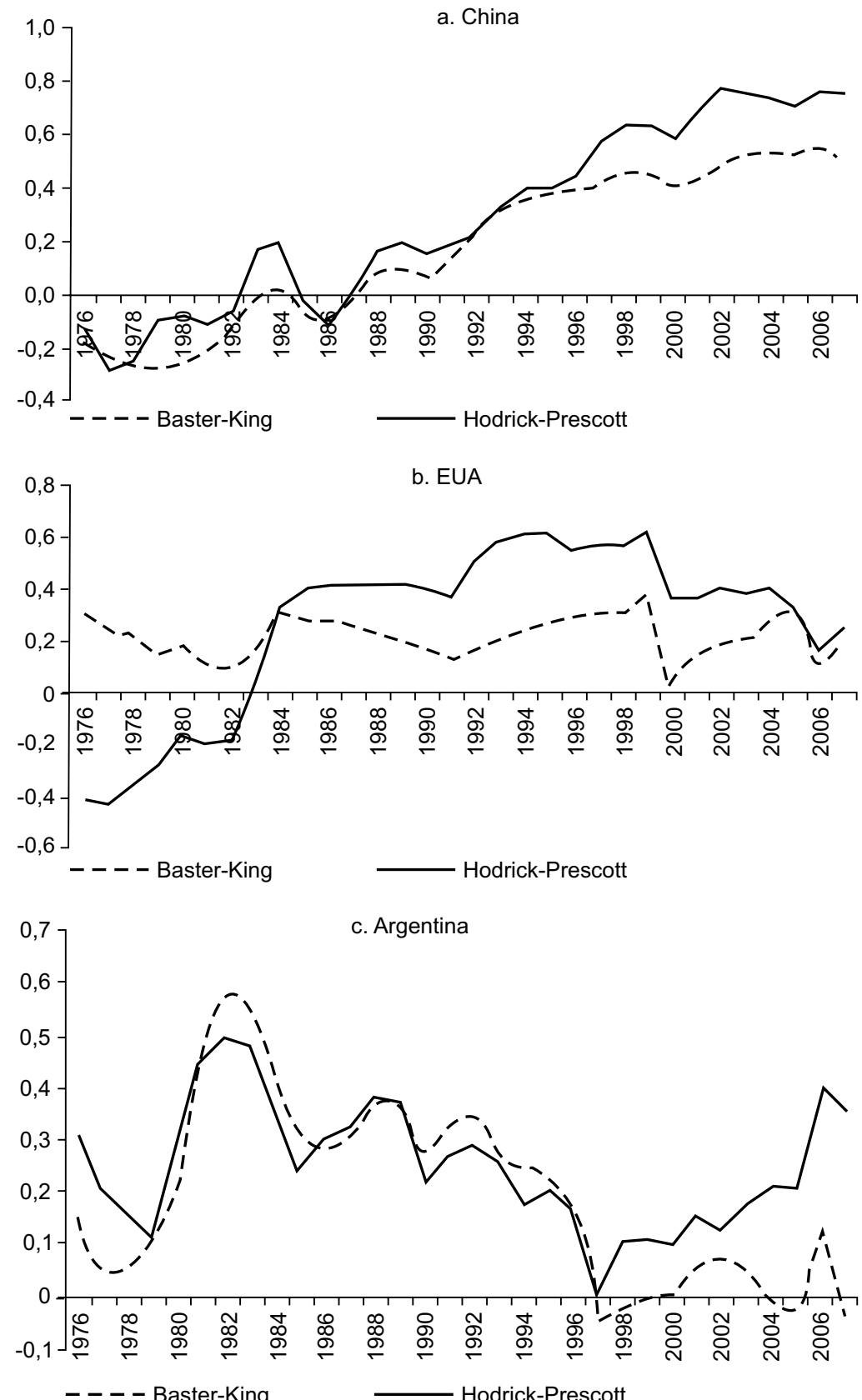

Nota: ${ }^{(*)}$ Os coeficientes de correlação dos ciclos econômicos foram calculados para períodos de 15 anos sucessivamente.

Fonte: Elaboração própria com dados do World Bank Indicators. 
Gráfico 4 - Indicador de intensidade de comércio em economias selecionadas, 1999-2008
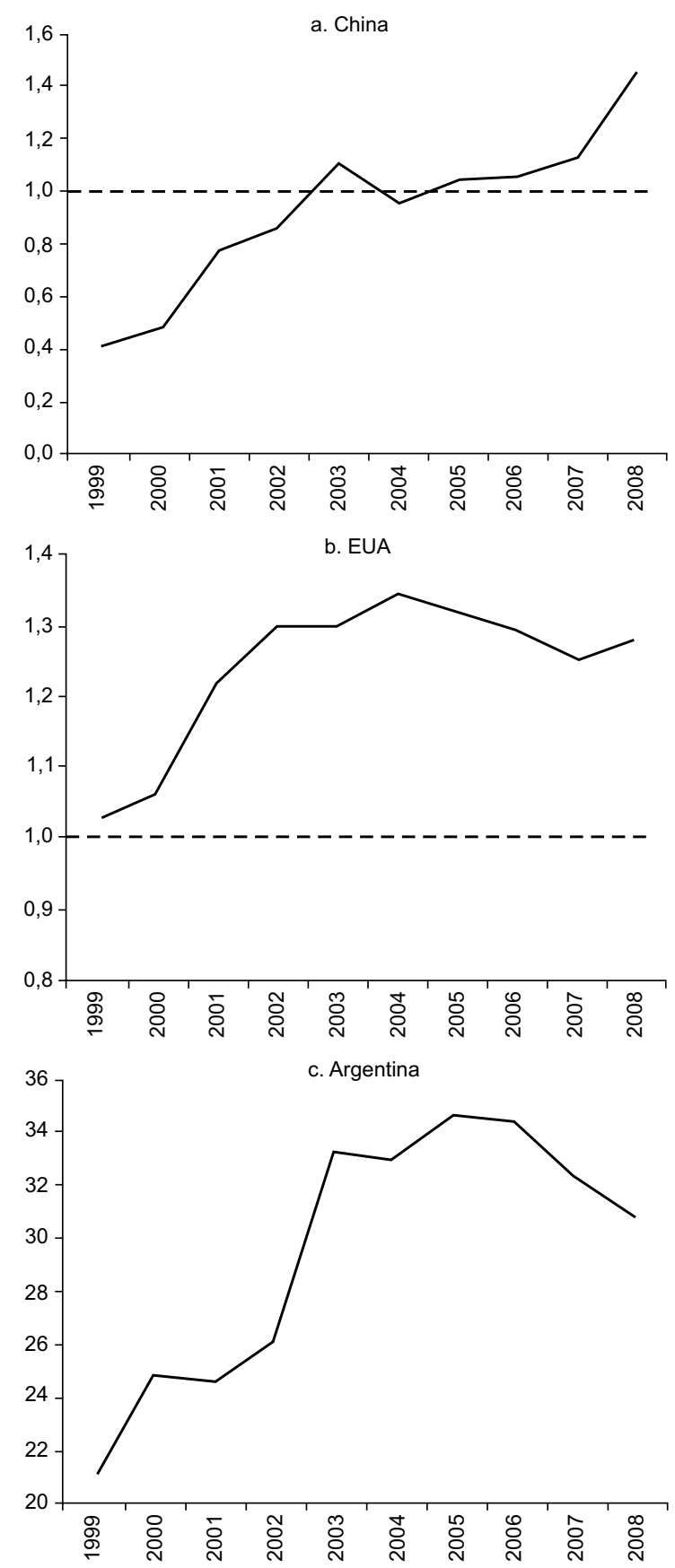

Fonte: Elaboração própria com dados do WDI-Banco Mundial. 


\section{Gráfico 5 - Indicador de comércio intrassetorial do Brasil com economias selecionadas, 1999-2008}

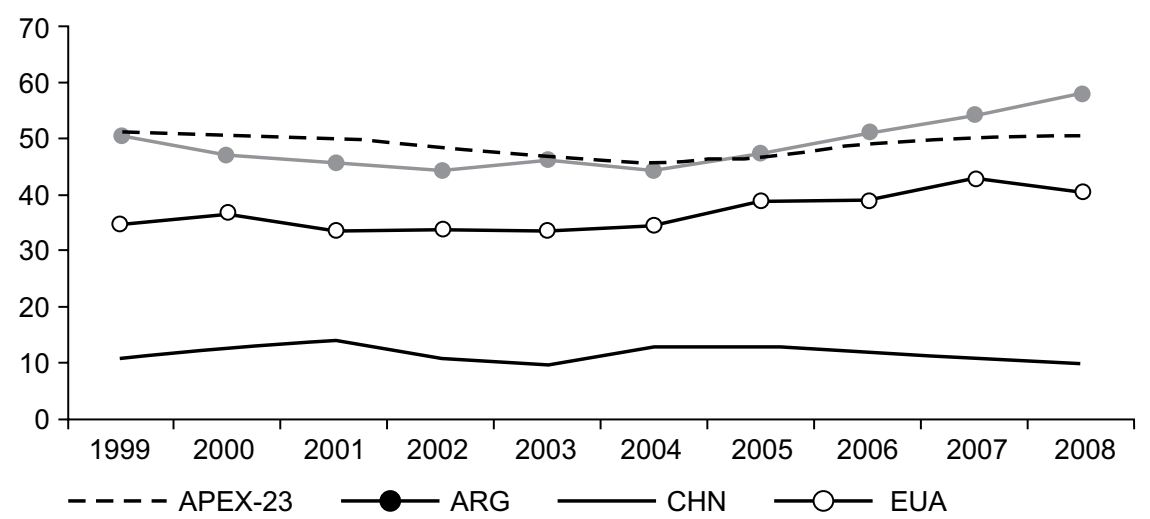

Fonte: Elaboração própria com dados do FMI-Directions Trade Statistics a três dígitos.

\section{REFERÊNCIAS}

(THE) ECONOMIST. Several Issues.

ACIOLY, L.; PINTO, E. C.; CINTRA, M. A. M. As relações bilaterais Brasil-China: a ascensão da China no sistema mundial e os desafios para o Brasil. Brasília: IPEA, 2011.

CORPORACIÓN ANDINA DE FOMENTO (CAF). América latina en el comercio global. Ganando mercados. Caracas: CAF, 2006.

CALDERÓN, C. Trade, specialization, and cycle synchronization: explaining output co-movement between Latin America, China, and India. In. LEDERMAN, D.; OLARREAGA, M.; PERRY, G. (eds.) China's and India's challenge to Latin American. Washington, DC: World Bank, 2008.

CALDERON, C.; CHONG, A.; STEIN, E. Trade Intensity and Business Cycle Synchronization: Are Development Countries Any Different? Journal of International Economics, v. 1, n. 71, 2007, p. 1-21.

COMISSÃO ECONÔMICA PARA A AMÉRICA LATINA E O CARIBE (CEPAL). La República Popular China y América Latina y el Caribe. Hacia una nueva fase en el vínculo económico y comercial, Junio. Santiago de Chile: CEPAL, 2011b. Disponível em http:// eclac.org.cl. Acesso em outubro de 2011.

Panorama de la inserción internacional de América Latina y el Caribe, 2005-2006. Santiago de Chile: CEPAL, 2006. Disponível em http://eclac.org.br. Acesso em outubro de 2011.

Panorama de la inserción internacional de América Latina y el Caribe, 2008- 2009. Crisis y espacios de cooperación regional. Santiago de Chile: CEPAL, 2009. Disponível em: http://eclac.org.br. Acesso em outubro de 2011. 
Panorama de la inserción internacional de la América Latina y el Caribe 2007, tendencias 2008. Octubre. Santiago de Chile: CEPAL, 2007. Disponível em: http://eclac. org.br. Acesso em outubro de 2011.

DEVLIN, R.; ESTEVADEORDAL, A.; RODRIGUEZ, A. (ed.). The Emergence of China: opportunities and challenges for the Latin America and Caribbean. Washington, DC: InterAmerican Development Bank and Harvard University, 2006.

EL-ERIAN, M. When markets collide: investment strategies for age of global economic change. New York: McGraw Hill, 2008.

FRANKEL, J.; ROSE, A. The endogeneity of the optimum currency area criteria. The Economic Journal, n. 108, 1998, p. 1.009-1.025.

FURTADO, C. Desenvolvimento e subdesenvolvimento. Rio de Janeiro: Fundo de Cultura, 1961.

FURTADO, C. Raízes do subdesenvolvimento. Rio de Janeiro: Civilização Brasileira, 2003.

GOLDMAN SACHS. BRICs and beyond. London: Goldman Sachs Global Economics, 2007. Disponível em http://www2.goldmansachs.com/our-thinking/brics/brics-and-beyond-book-pdfs/brics-full-book.pdf. Acesso em 02 de dezembro de 2011.

JENKINS, R. China's Global Expansion and Latin America. Journal of Latin American Studies, v. 42, part. 4, November, 2010, p. 809-837.

LEDERMAN, D.; OLARREAGA, M.; PERRY, G. (ed.) China's and India's challenge to Latin American. Washington, DC: World Bank, 2008.

LEONARD, M. O que a China pensa? São Paulo: Larousse, 2008.

MOREIRA, M. M. Fear of China: is there a future for manufacturing in Latin America? Occasional Paper, INTAL/ITD, n. 36, 2006.

PAUS, E. The rise of China: implications for Latin American development. Development Policy Review, v. 27, n. 4, 2009, p. 419-56.

PHILLIPS, N. "Consequences of an emerging China: is development space disappearing for Latin and the Caribbean?" Centre for International Governance Innovation, Working Paper, n. 14, 2007.

PREBISCH, R. Economic survey of Latin America, 1949. New York: United Nations, 1950.

PREBISCH, R. "Five Stages in my thinking on development". In: MEIER, G. M.; SEERS, D. (ed.). Pioneers in Development. Oxford: Oxford University Press, 1984.

RANA, P. B. Trade intensity and business cycle synchronization: the case of East Asia. Working Paper Series on Regional Economic Integration, ADB, Asian Development Bank, n. 10, 2007.

SHIN, K.; WANG, Y. Trade integration and business cycle synchronization in East Asia. Asian Economic Papers, v. 2, n. 3, 2004.

SHIRK, S. L. China fragile superpower. Oxford: Oxford University Press, 2007. 
SINNOT, E.; NASH, J.; DE LA TORRE, A. Natural resources in Latin America and the Caribbean

- beyond booms and busts? Washington, DC: The World Bank, 2010.

TRINH, T.; VOSS, S.; DICK, S. China's commodity hunger: implications for Africa and Latin America. Frankfurt: Deustche Bank Research, 2006. Disponível em www.dbresearch.com. Acesso em janeiro de 2007.

WU JIGLIAN. “Does china need to change its industrializations path?” In: GILL, I.; HUANG, Y.; KHARAS, H. (ed.). East Asian visions. Washington: World Bank, 2006.

WU JIGLIAN. Understanding and interpreting Chinese economic reform. Mason: Thomson, 2005.

ZHENG BIJIAN. China's Peaceful Rise: Speeches of Zheng Bijian 1997-2004. Washington, DC: The Brookings Institution, 2005. Disponível em http://www.brookings.edu/events/ 2005/0616china.aspx. Acesso em setembro de 2011.

ZHENG BIJIAN. "The internal and external environments of China's development over the next five years". In: GILL, I.; HUANG, Y.; KHARAS, H. (ed.). East Asian visions. Washington: World Bank, 2006. 